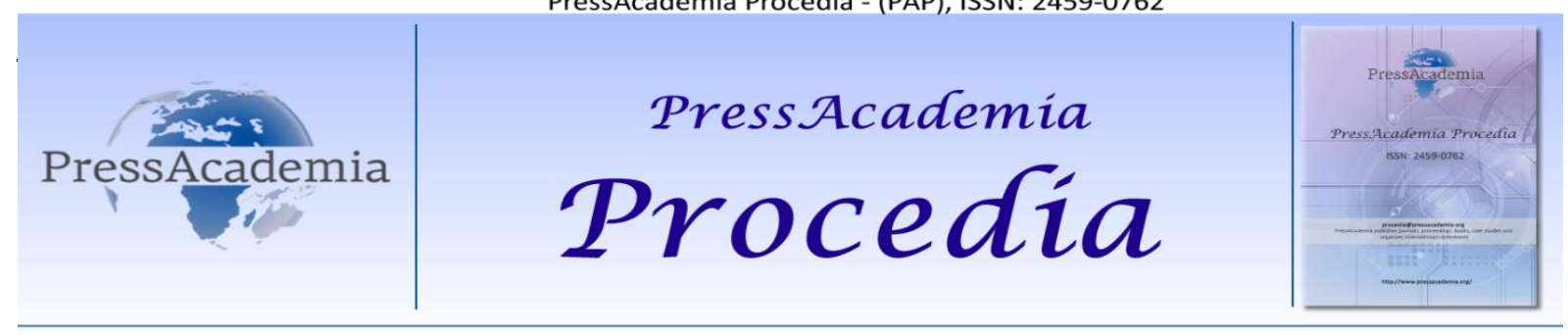

Global Business Research Congress (GBRC), May 24-25, 2017, Istanbul, Turkey.

\title{
A LITERATURE REVIEW ON INTERMODAL TRANSPORTATION
}

DOI: 10.17261/Pressacademia.2017.387

PAP-GBRC-V.3-2017(2)-p.9-20

\section{Gokhan Aldemir, Tugce Beldek}

Istanbul Technical University, Management Faculty, Macka 34367, i̇stanbul, Turkey. aldemirg@itu.edu.tr

Istanbul Technical University, Management Faculty, Macka 34367, istanbul, Turkey. beldek@itu.edu.tr

\section{To cite this document}

Aldemir, G., T: Beldek. (2017).A literature review on intermodal transportation. PressAcademia Procedia (PAP), V.3, p.9-20

Permemant link to this document: http://doi.org/10.17261/Pressacademia.2017.387

Copyright: Published by PressAcademia and limited licenced re-use rights only.

\begin{abstract}
As an important part of global trade, freight transport has grown rapidly over the past two decades. Designing cost effective and highly efficient transport networks is extremely important in freight transport. The main modes of transport are air, rail, road and sea. Although road transport still constitutes a significant part of freight transport, intermodal transport is a preferred alternative for establishing a sustainable transport system. Intermodal transport can be defined as the transport of goods in the same transport (loading) unit using two or more modes of transport together, and the handling of the goods rather than the goods themselves. The use and development of intermodal transport have numerous economic, social and environmental advantages. In this study, a detailed literature search is presented by various classifications on intermodal freight transport problems; suggestions for future work have been made.
\end{abstract}

Keywords: Intermodal transport, freight transport planning, literature review, sustainable transportation, transportation network design JEL Codes: L91, L92, L93

\section{INTERMODAL TAŞIMACILIK ÜZERINE DETAYLI BIRR LITERATÜR TARAMASI}

\section{ÖZET}

Küresel ticaretin önemli bir parçası olarak yük taşımacılığı son yirmi yılda hızlı bir büyüme göstermiştir. Maliyet etkin ve yüksek düzeyde verimli taşıma ağları tasarlamak yük taşımada son derece önemlidir. Ana taşıma modları havayolu, demiryolu, karayolu ve deniz yoludur. Karayolu taşımacılığı halen yük taşımacılı̆ıını önemli bir bölümünü oluşturmasına rağmen, intermodal taşımacılık sürdürülebilir taşıma sistemi oluşturmak için tercih edilebilir bir alternatiftir. İntermodal taşımacııık iki veya daha fazla taşıma modunun birlikte kullanılarak ürünlerin aynı taşıma (yükleme) birimi içinde taşıma modu değişikliği yaparken malların kendisinin değil taşıma biriminin elleçlenerek taşınması olarak tanımlanabilir. İntermodal taşımacılık koridorlarının kullanımı ve geliştirilmesinin ekonomik, sosyal ve çevresel çok sayıda avantajı vardır. Bu çalışmada intermodal yük taşımacılığı problemleri üzerine çeşitli sınıflandırmalar yapılarak detaylı bir literatür araştırması sunulmuştur; gelecek çalışmalar için öneri yapılmıştır.

Anahtar Kelimeler: Intermodal taşımacılık, yük taşımacılığı planlaması, literatür araştırması, sürdürülebilir taşımacılık, taşımacılık ağ tasarımı.

JEL Kodları: L91, L92, L93 


\section{GíRiş}

Toplumların ekonomik büyüme ve sosyal gelişiminde önemli rol oynayan taşımacılık genel olarak bir noktadan diğerine insan ve yük transferi olarak tanımlanabilir. Küresel ticaretin önemli bir parçası olarak yük taşımacılığı son yirmi yılda hızlı bir büyüme göstermiştir. Tedarikçiler, üreticiler ve müşteriler arasındaki artan mesafeler, özellikle son yıllarda ulusal ve uluslararası taşımacılık operasyonlarının da artmasına neden olmuştur (Demir vd., 2015). Maliyet etkin ve yüksek düzeyde verimli taşıma ağları tasarlamak yük taşımacılığında son derece önemlidir. Lojistik yönetiminde önemli yer teşkil eden taşıma türleri iki ana gruba ayrılmaktadır: Tek-modlu (karayolu, demiryolu, havayolu, denizyolu/nehir-iç suyolu ve boru hattı taşıma) ve çok-modlu taşıma yöntemleri. Karayolu taşımacılığı halen yük taşımacılığının önemli bir bölümünü oluşturmasına rağmen, başlangıç noktasından varış noktasına en az iki farklı taşıma modu kullanılarak gerçekleştirilen taşıma faaliyeti olarak tanımlanan çok modlu taşımacılık sürdürülebilir taşıma sistemi oluşturmak için tercih edilen bir alternatiftir (Zhang vd., 2015). Günümüzde uluslararası ticaretin de etkisiyle, ulaştırma faaliyetlerinin en verimli şekilde gerçekleştirilmesini sağlayan çok modlu taşıma sistemleri yaygın olarak kullanılmaya başlanmıştır. Çok modlu taşımacılığın özel bir türü olarak intermodal taşımacılık ise, tek yüklemeyle ve aynı taşıma birimi içinde ürünlerin elleçleme yapılmadan, birden çok taşıma modu kullanılarak taşınması olarak tanımlanmaktadır. Burada, konteyner taşımacılığı veya yüklemede ağzı kapatılan ünitenin hiç açılmadan karayolu, demiryolu veya denizyolu gibi en az iki taşıma modu ile taşınarak teslim yerinde açılması kastedilmektedir. Intermodal taşıma ağı yük terminalleri, depolar, transfer noktaları, taşıma koridorları ve lojistik merkezlerinden oluşan dağıtık bir sistemdir. Gelişmekte olan bir araştırma alanı olarak intermodal taşımacılık koridorlarının tasarlanması ve kullanımı, tek bir taşıma modunun dengesiz kullanımı ile karşılaştırıldığında ekonomik, sosyal ve çevresel çok sayıda avantaja sahiptir. Bu avantajlardan bazıları; verimlilik, düşük maliyet (uzun mesafeli taşımada), güvenilirlik, azalan trafik yoğunluğu, çevreye duyarlı taşıma, zamanında teslim, taşıma risklerinde azalma (trafik kazaları vb.) ve farklı taşıma türlerinin entegrasyonundan sağlanan yararlar (karayolu taşımacılığının esnekliği, demiryolu taşımacılığının yüksek hacimli yük kapasitesi, denizyolu taşımacılığında düşük maliyet, havayolu taşımacılığında yüksek hız vb.) olarak sıralanabilir (Ziliaskopoulos ve Wardell, 2000). İntermodal taşımacııı̆ın dezavantajları ise kısa mesafeli taşımalar için yüksek maliyetli olması, lojistik merkez/köylere duyulan ihtiyaç, tek modlu taşıma sistemine göre daha karmaşık olması, taşıma birimlerinin diğer modlara uyum sağlama zorunluluğu, yetişmiş eleman ihtiyacı, yazılım desteği ve bu alanda araştırma çalışmalarındaki eksiklikler olarak belirtilebilir.

Intermodal taşımacııık sistemlerinin çok aşamalı ve karmaşık yapılar olması sebebi ile sistemin her aşamasında farklı problemlere çözüm getirilmesi gerekmektedir. Intermodal taşımanın oluşturulmasında, taşıma koridorları boyunca altyapı iyileştirmenin yanı sıra, çoğunlukla yöneylem araştırması teknikleri uygulanarak farklı senaryolar ve maliyetler altında ağ tasarım modelleri ve çözüm yaklaşımlarını değerlendirmek yolu ile karar vericiye destek olan karar destek araçlarına ihtiyaç duyulur (Regmi ve Hanaoka, 2012; Meisel vd., 2013). Son yıllarda literatürde artan sayıda çalışmanın çok modlu ve intermodal taşımacılık sistemlerinde planlama problemlerini ele aldığı ve uygulayıcılar ve araştırmacılar tarafından intermodal yük taşımacılığının yoğun ilgi görmeye başladığı görülmektedir.

Bu çalışmada, intermodal taşıma üzerine 1994-2016 yılları arasında intermodal taşımacılık üzerine yapılan 50 çalışma sınıflandırılmıştır. Çalışmalar planlama ufkuna göre stratejik, operasyonel ve taktiksel olarak üçe; problem özelliğine göre statik-deterministik, statik-stokastik, dinamik-determistik ve dinamik-stokastik olmak üzere dörde, çalışmanın amacına göre kar maksimizasyonu, maliyet minimizasyonu, süre minimizasyonu, karbon emisyonu minimizasyonu, maliyet karşılaştırma ve performans karşılaştırma, araç sayısı minimizasyonu, risk minimizasyonu, optimal yer seçimi ve optimal rota seçimi şeklinde sınıflandııımıştır. Modelleme ve çözümde kullanılan yönteme göre de sınıflandırma yapılmıştır. Ayrıca benzetim ve bulanık kümeler yöntemi konuyla ilgili birçok çalışmada yer aldığından bu yöntemlerin kullanılıp kullanılmamasına göre de sınıflandırma yapılmıştır.

Çalışmanın ikinci bölümünde, tüm çalışmalar kısaca açıklanmış, seçilen üç çalışma detaylandırıımıştır, üçüncü bölümünde çalışmalar yukarıda bahsedildiği gibi sınıflandırılacaktır. Dördüncü bölümde sınıflandırmaların sonuçları analiz edildikten sonra son bölümde analiz sonuçlarına göre gelecek çalışmalar için öneriler sunulacaktır.

\section{LITERATÜR INCELEMESi}

Morlok ve Spasovic (1994) intermodal karayolu-demiryolu yük taşımacılığında kamyonla yapılan parça yük taşımacılığı ile ilgili nakliye operasyonları optimizasyon problemini tam sayılı doğrusal programlama modeliyle formüle etmişlerdir.

Southworth ve Peterson (2000) intermodal yük hareketlerinin rotalanması üzerine odaklanmışlardır. Rotalar karayolu, demiryolu ve denizyolu taşıma modlarının farkıı kombinasyonlarını içermektedir. Çalışmada, Coğrafik Bilgi Sistemleri (GIS) teknolojisi kullanılmıştır. İntermodal yük sevkiyatlarında rekabetçi ve etkin bir rotalama için GIS çok etkili ve başarılı olarak kullanılmıştır. 
Sook ve diğerleri (2002) intermodal ulaştırma ağları için boş konteyner yönetimi üzerine planlama ufkunun uzunluğunun etkisini hesaplamalı bir analizle sunmuşlardır. Analiz, boş konteynerlerin taşınmasıyla ilgili toplam masrafları en aza indirgemeyi amaçlayan bir tam sayılı programlamaya dayanmaktadır ve Mississippi Nehri havzasındaki mavna operasyonlarının potansiyel konteyner üzerinde yapılan vaka incelemesi, ufuk uzunluğunun planlanmasının mod seçimi üzerindeki etkilerini göstermektedir. Wang ve Regan (2002) demiryolu ve deniz yolu intermodal taşımacılığını destekleyen yerel kamyon yükleme ve teslim operasyonlarında araç atamalarının geliştirilmesi için bir çözüm yöntemi sunmuşlardır. Problemin kısıta bağı ıe kısıttan bağımsız versiyonları iki ayrı iterasyonda çözülmüştür. Küçük boyutlu fakat gerçek hayat problemler üzerinde yapılan uygulama sonuçları göstermiştir ki, dar bölümleme aralıkları çözüm süresini uzatsa da daha iyi sonuçlar vermektedir.

Zhang vd. (2003) intermodal terminallerde karşılaşılan depo alanı tahsis etme problemi üzerinde çalışmışlardır. Dönen planlama ufku yaklaşımı kullanılarak çözülen problem dünyanın en yoğun konteyner limanı olan, Hong Kong limanında uygulanmıştır. Yapılan çalışma sonrası önemli ölçüde iş yükü dengesizliğinin azaldığı görülmüştür.

Arnold vd. (2004) intermodal yük taşımacılığında demiryolu/karayolu terminallerinin en uygun yer seçimi problemini ele almışlardır. Tam sayılı doğrusal programlama ile formüle edilen problem sezgisel yaklaşım kullanılarak çözülmüştür. Önerilen yaklaşım İspanyanın ỉber yarımadasında mevcut demiryolu/karayolu taşımacılık sistemine uygulanmıştır. Bu araştırma sonrası terminal yerleşim yerleri optimizasyonunun Avrupa taşımacılık sisteminin genelinde olumlu sonuçlar oluşturacağı vurgulanmıştır.

Parola ve Sciomachen (2005) tarafından İtalya'nın Kuzey Batısındaki liman sistemini kapsayan lojistik zincirine ilişkin ayrık olaylı benzetim yaklaşımı sunularak, konteyner akışındaki olası büyümenin değerlendirilmesini amaçlanmıştır. Çalışmada, intermodal ağın lojistik aktivitelerinin problem ve özelliklerinin önemini ortaya koyan benzetim modelleri analiz edilmiştir. Yazarlar, deniz trafiğinin 2002-2012 yılları arasında sabit büyüdüğünü kabul ederek, bu büyümenin karayolu altyapısı üzerindeki etkisini analiz edip üç farklı senaryoyu değerlendirmiştir. Deneysel sonuçların karşılaştırılması ile en iyi ve en kötü konfigürasyonlar belirlenmiştir.

Janic (2007) intermodal taşımacılık (demiryolu ve karayolu) ve sadece karayolunun kullanıldığı tek modlu taşımacılık ağlarının içsel ve dışsal maliyetlerinin kombinasyonunu kıyaslamak için bir model geliştirmiştir. Modelde iç maliyetler; intermodal terminal operatörleri ve taşıma yolu ile gerçekleşen maliyetlerin yanı sıra, malların transit geçişine ilişkin zaman maliyetlerini içermektedir. Her iki taşıma ağının da daha çok sosyal ve çevresel etkilerini kapsayan dış maliyetler ise; yerel ve küresel hava kirliliği, gürültü ve trafik kazaları gibi maliyetleri içermektedir. Avrupa yük taşıma sisteminden alınan gerçek veriler kullanılarak uygulanan model göstermiştir ki, kapıdan kapıya teslim mesafesi artıkça her iki durumda da toplam maliyetler azalmıştır. Diğer yandan, ortalama maliyet ise yükleme miktarı arttıkça intermodal taşıma ağında azalan oranda düşerken, karayolu taşımacılık ağında sabit kalmaktadır.

Uluslararası intermodal ağ sevkiyatları için en iyi rota seçimi problemi Chang (2008) tarafından ele alınmıştır. Ele alınan problem çoklu amaçlar, çizelgelenmiş taşıma modları ve planlanan teslim sürelerinin yanı sıra taşıma ölçek ekonomisi nedeniyle oldukça karmaşık bir yapıya sahiptir. Sözkonusu problem zaman pencereli ve içbükey maliyet fonksiyonlu çok amaçlı, çok modlu çoklu-ürün akış problemi olarak formüle edilmiştir. Problemin temel karakteristiklerini kapsayan bir matematiksel model geliştirilmiş olup önerilen sezgisel bir algoritma ile problem etkin bir şekilde çözülmüştür. Orijinal problemi daha küçük ve kolay alt problemlere ayırmak için gevşetme ve ayrıştırma tekniklerinden yararlanılmıştır.

Hanaoka (2009) intermodal taşımacılıkta lojistik performanslarının çok kriterli ve bulanık tabanlı olarak değerlendirmesini sunmuştur. Çalışmada, karar vermede yaşanılan belirsizliklerle başa çıkmak için bulanık küme teorisinden yararlanılmıştır. Bu kapsamda, Tayland'da faaliyette bulunan on dört lojistik şirketi ile yapılan görüşmelerde uzmanların bakış açıları belirlenmiştir. Gerçekleştirilen uygulamada, bulanık-analitik hiyerarşi prosesi ve bulanık-çok kriterli karar verme teknikleri birleştirilerek performans değerleri elde edilmiştir.

Carolin ve Hartmut (2010) intermodal bir nakliye zincirinin üç farklı aşamasında faaliyet gösteren bağımsız servis sağlayıcılarının eşgüdümünü inceleyen sayısal bir işbirlikçi planlama yaklaşımı sunulmuştur. Bu nedenle, tüm taraflar planlama alanlarında faaliyet gösterirken yalnızca kritik olmayan verileri değiştirilerek genel ulaşım maliyetlerinde önemli düşüşlere yol açan bir eşgüdüm şeması geliştirilmiştir. Aynı yıl, Bauer ve arkadaşları (2010) çevreyle ilişkili maliyetleri nakliye taşımacılığı planına dahil etme konusuna değinerek diğer çalışmalardaki yaklaşımdan kopar ve maliyet ve sera gazı emisyonlarının miktarını en aza indirgerken çoklu ürün kalitesini maksimize eden kapasite kısıtlı ağ tasarım formülü şeklinde bir tam sayı programı önermişlerdir. Sawadago ve Anciaux (2010) Paris ve Marsilya arasında gerçekleştirilen yük taşımacılığında on iki rotanın dikkate alındığı vaka çalışmasında çok-kriterli karar verme metotlarından AHP ve ELECTRE metotlarını kullanarak en optimal rotayı seçmişlerdir. Diğer bir çalışmada ise, intermodal yük lojistiğinde yerleşim kararları için kavramsal bir model Kayıkçı (2010) tarafından geliştirilmiştir. Bu çalışmanın amacı uygun yer seçimi için karar vericilerin karar verme aşamalarını çok-kriterli ve çok-seviyeli karar verme metotlarını kullanarak kolaylaştırmaktır. Bu amaçla, bulanık- 
AHP ve yapay sinir ağı teknikleri kullanılarak problemdeki önemli ağırlık faktörleri belirlenmiş ve verilen seçim alternatifleri içinde intermodal yük lojistik merkezinin en iyi yer seçimi yapılmıştır.

Yang vd. (2011) Çin'de iki önemli başlangıç noktasından, Hindistan'da 4 önemli varış yerine yük taşıması yapılan 36 adet alternatif güzergahın değerlendirilmesi amacıyla intermodal yük taşıma optimizasyon modeli geliştirmişlerdir. Hedef programlama ve maliyet modeli bileşenlerinden oluşan model, farklı modlar arasında yük akışının sürekliliğinin sağlanması ve yük aktarması yapılacak düğümlerinin birbiriyle uyumunun dikkate alınmasının yanı sıra, taşıma maliyeti, transit süre ve transit süre değişkenliği minimizasyonu gibi birbiriyle çelişen farklı hedeflerin aynı anda dikkate alınmasını hedeflemiştir. Macharis ve Jourquin (2011) intermodal taşımacılık politikaları üzerine genel bir değerlendirme çerçevesi oluşturmak için çok katlı bir nakliye modeli (NODUS), iç suyolu ağının ve terminallerinin ayrık bir olay simülasyonu modeli (SIMBA) ve Belçika intermodal terminaller için konum analizlerini destekleyen LAMBIT modeli olmak üzere üç temel model geliştirmişlerdir. Üç modelin kombinasyonu, karmaşık taşımacılık endüstrisini desteklemek ve nakliye altyapı ağında olası sorunları öngörmek için politika üretmeye olanak tanıyan bir karar destek sistemi oluşturmaktadır. Meng ve Wang (2011) intermodal toplama ve dağıtım ağı tasarım problemi için denge kısıtlı matematiksel bir model geliştirmişlerdir. Amaç fonksiyonunun toplam taşıma maliyetinin minimizasyonu olduğu modelde asimetrik yük akışı atama sorununu çözmek için köşegenleştirme metodu ile birlikte bir hibrit genetik algoritma kullanılmıştır. Yang vd. (2011) Çin'de iki önemli başlangıç noktasından, Hindistan'da 4 önemli varış yerine yük taşıması yapılan 36 adet alternatif güzergahın değerlendirilmesi amacıyla intermodal yük taşıma optimizasyon modeli geliştirmişlerdir. Hedef programlama ve maliyet modeli bileşenlerinden oluşan model, farklı modlar arasında yük akışının sürekliliğinin sağlanması ve yük aktarması yapılacak düğümlerinin birbiriyle uyumunun dikkate alınmasının yanı sıra, taşıma maliyeti, transit süre ve transit süre değişkenliği minimizasyonu gibi birbiriyle çelişen farklı hedeflerin aynı anda dikkate alınmasını hedeflemiştir.

Bruns ve Knust (2012) intermodal konteyner terminallerindeki trenler için yük planlaması problemi incelemişlerdir. Amaç, bir trenin vagonlarına trenin kullanım oranını en üst seviyeye çıkaracak ve yük birimlerini atamak ve terminaldeki kurulum ve taşıma maliyetlerini en aza indirecek şekilde byük birimlerini atamaktır. Önceki yaklaşımların aksine, vagonlar için ağırlık kısıtlamaları modele entegre edilmiştir. Üç farklı tamsayılı doğrusal programlama formülasyonunu sunup ve bazı gerçek dünya örneklerinde test etmişlerdir. Regmi ve Hanaoka (2012) operasyonlar ve altyapı bakımından Kuzey Doğu ve Orta Asya'yı birbirine bağlayan iki önemli intermodal taşımacılık koridorunu değerlendirmişlerdir. Koridorlarda yüklerin taşınması için kara, deniz ve demiryolu modları kullanılmaktadır. Çalışmada koridorların fiziksel altyapı durumlarının yük taşıma operasyonları için gerekli olan sınır geçiş imkanları ve fiziksel olmayan darboğazları incelenmiştir. İntermodal taşıma koridorlarının performanslarının değerlendirilmesi ve karşılaştııılması için zaman-maliyet-mesafe yaklaşımı kullanılmıştır. Sonuç olarak, taşıma koridorlarının operasyonel verimliliğini artırmak için fiziki olmayan engelleri en aza indirmek ve fiziki altyapıyı geliştirmek için politik önerilerin sunulmasının Asya'daki ülkeler ve diğer ülkeler için yararlı olacağı ve her iki koridorda da operasyonel hizmetlerin ve intermodal ulaştırma altyapılarının geliştirilmesinin önemine değinilmiştir.

Meisel vd. (2013) bu alandaki çalışmaların literatürde az olduğuna değinerek tedarik ağında intermodal taşıma planlaması ve üretim kombinasyonu üzerine bir model sunmuşlardır. Problemi çözmek için dal-kesme metodu ve ayrıştırma-tabanlı sezgiseller geliştirilmiştir. Yazarlar kimya sektöründe faaliyette bulunan bir şirkette kapsamlı bir vaka çalışması gerçekleştirmiştir. Önerilen entegre planlama sonrası \%6 maliyet tasarrufu olduğu belirtilmiştir. Böylece şirkette çevre dostu dağııım proseslerinin oluşturulması da başarıyla desteklenmiştir. Saeed (2013) iki farklı ulaşım aracı ile üç farklı taşıyıcı arasındaki yatay ve dikey işbirliklerini analiz etmiştir. Önerilen analizde, iki-aşamalı oyun teorisi yaklaşımı kullanılmıştır. Garcia ve diğerleri (2013) karmaşık intermodal taşıma problemlerine hitap eden yeni bir hibrid yaklaşım geliştirmişlerdir. Her iki tekniğin de avantajlarından yararlanarak kaliteli çözümler elde etmek için Yöneylem Araştırması ve Yapay Zeka'nın Arama tekniklerini birleştirmişlerdir. Çözüm, İspanya'nın en büyük intermodal taşımacılık yapan Acciona Transmediterránea Cargo şirketinde gerçek bir dünya soruna uygulanmıştır. Saatçioğlu ve Saygılı (2013) yük taşımacılığında maliyet, mesafe, zaman, çevre, enerji ve trafik sıkışıklığı konularını ele alarak, intermodal taşımacılıkta denizyolu-demiryolu entegrasyonunun sağlanmasında hangi etmenlerin etkili olduğunu operasyon maliyetlerini karşılaştııılarak araştırmışlardır. Sonuç olarak mikro ölçekte işletmeler, makro ölçekte ise ulaştırma politikaları açısından uygulama çalışmaları değerlendirilmiştir. Bu değerlendirmede, çevreye daha duyarlı iki taşıma türü demiryolu ve denizyolu taşımacııı̆ını teşvik edici önlemler almamııın önemi vurgulanmaktadır.

Chang ve Lai (2013) farklı tahsisat politikaları için geliştirilen matematiksel modeller ile karbon emisyon kotalarının, taşıma talebi, toplam gelir ve taşıma ücret oranları üzerindeki etkilerini araştırmışlardır. Yazarlar, kuzey-doğu Tayvan'daki kum endüstrisinde tek-modlu ve intermodal taşımacılık üzerindeki karbon emisyon seviyelerinin etkileri ve endüstriye sağladı̆̆ı getiriyi değerlendirmişlerdir. Çalışmanın sonucunda, serbest karbon kotaları azaldıkça, taşıma endüstrisindeki gelirin üzerindeki negatif etkisine rağmen intermodal sistemler için talebin arttığı görülmüştür.

Zehendner ve Feillet (2014) kamyon atama problemini çözmek için terminaldeki gecikmeleri minimize etme amaç fonksiyonuna sahip bir karma tam sayılı doğrusal programlama modeli önermişlerdir. Çalışmada, eş zamanlı olarak kamyon 
atama sayıları belirlenirken farkı taşıma modları için liman istifleme taşıyıcılarının tahsisi de dikkate alınmıştır. Geliştirilen model Marsilya'daki Grand Port Maritime'da faaliyette bulunan bir konteyner terminalinde karşılaşılan gerçek-hayat problemler üzerinde test edilmiştir.

Assadipour ve diğerleri (2015) intermodal taşımacılıkta tehlikeli yükleri yönetmek için iki amaçlı bir optimizasyon çerçevesi önermekle birlikte bu boşluğu kapatmaya çalışmışlardır, sadece açık alanlardaki karışıklıkları çözmeye yönelik değil aynı zamanda uygun ekipman kapasitesini de belirtmişlerdir. Önerilen çerçeve, yani doğrusal olmayan bir karma tamsayılı programlama ve çok amaçlı bir genetik algoritmaya dayalı çözüm metodolojisi, mevcut literatürden gerçekçi problem örneğine uygulanmıştır.

Bir coğrafik bölgedeki intermodal taşıma ağının tasarım ve operasyonu için farklı taşıma modlarının entegre edildiği çokamaçlı bir optimizasyon modeli Reşat ve Türkay (2015) tarafından sunulmuştur. Problem süre ve trafik sıkışıklığına bağlı araç hızlarının dikkate alındığı bir karma-tam sayılı matematiksel model olarak formüle edilmiştir. Arttırılmış-kısıt metodu kullanılarak eş zamanlı olarak süre ve taşıma maliyeti minimizasyonları için matematik programlama probleminin önemli karakteristik çıktıları ve veri analizi yaklaşımı modellemede sunulmuştur. Önerilen yaklaşım Türkiye'nin Marmara bölgesinden elde edilen veriler kullanılarak bir gerçek-hayat intermodal taşıma problemine uygulanmıştır. Santos vd. (2015) Avrupa'da demiryolu-karayolu intermodal taşımacılığı teşvik etmeyi amaçlayan yük ulaştırma politikalarının etkilerini araştırmışlardır. Yazarlar ana dağııı üssü-yerleşim teorisi temeline dayanan bir karma tam sayılı matematiksel model önermişlerdir. Çalışmada doğrusal olmayan taşıma maliyetleri dikkate alınmıştır. Belçika'da yer alan bir vaka analiz çalışması sonucunda, intermodal taşımanın taşınan miktarlar üzerinde önemli bir etkisi olduğu ve terminal yeri optimizasyonunun intermodal taşıma rekabetini arttırdığı görülmüştür. Zhang vd. (2015) eş zamanlı olarak çok modlu alt yapı, ana dağıtım üssü tabanlı hizmet ağı yapısı ve çoklu aktörlerin çeşitli tasarım hedeflerini içeren bir yük taşıma optimizasyon modeli sunmuşlardır. Tasarım problemi iki-seviyeli optimizasyon modeli ile çözülmüştür. Alt seviyede çok modlu büyük boyutlu bir ağ üzerinde çoklu ürün akış ataması gerçekleştirilirken, üst seviyede ise farklı politika ölçütlerinin optimum kombinasyonları araştırımıştır. Hollanda'nın coğrafik yapısı ve diğer Avrupa ülkeleri ile olan bağlantıları göz önüne alınarak Rotterdam limanında bir vaka çalışması gerçekleştirilmiştir. Çalışmanın sonuçları farklı aktörler arasındaki etkileşimlerin yanı sıra alt yapı ağı, hizmet ağı ve düzenleyici politikalar arası ilişkiler üzerinde açıklayıcı olmuştur.

Baykasoğlu ve Subulan (2016) müşterilerin ulaşım taleplerini ve diğer birçok ilgili konuyu karşılamak için ithalat/ihracat yük akışlarını göz önüne alarak, çok amaçlı, çok modlu ve çok dönemli bir yük planlama problemi için karma tamsayılı bir matematiksel programlama modeli sunmuşlardır. Bulanık karar verme ortamında çelişen hedefleri eş zamanlı olarak ele almak için çoklu nesnel optimizasyon prosedürü kullanılmıştır. Önerilen modelin uygulanması ve yararılığını sunmak için gerçek hayatta bir vaka çalışması da yapılmıştır. Yakın zamanda gerçekleştirilen bir çalışmada ise, Lin ve Lin (2016) tarafından intermodal terminal yerleşim problemi için iki-aşamalı çözüm yaklaşımı ile birlikte etkili bir sezgisel önerilmiştir. Toplam taşıma ve operasyonel maliyetlerin minimizasyonunu amaçlayan problem intermodal taşıma ağını oluşturan terminallerin seçimi ve yük akışlarının rotalanmasını içermektedir.

\section{3. ÇALIŞMALARIN SINIFLANDIRILMASI}

Çalışmada intermodal taşıma üzerine 1994-2016 yılları arasında intermodal taşımacılık üzerine yapılan 50 çalıșma sınıflandırılmıştır. Çalışmalar planlama ufkuna göre stratejik, operasyonel ve taktiksel olarak üçe; problem özelliğine göre statik-deterministik, statik-stokastik, dinamik-determistik ve dinamik-stokastik olmak üzere dörde, çalışmanın amacına göre kar maksimizasyonu, maliyet minimizasyonu, süre minimizasyonu, karbon emisyonu minimizasyonu, maliyet karşılaştırma ve performans karşılaştırma, araç sayısı minimizasyonu, risk minimizasyonu, optimal yer seçimi ve optimal rota seçimi şeklinde sınıflandııımıştır. Makalelerin detaylı sınıflandırma tablosu Ek.A'da verilmiş olup, Şekil 1 yıllara göre makale sayılarını göstermektedir.

Şekil 1: Yıllara Göre Makale Sayıları 


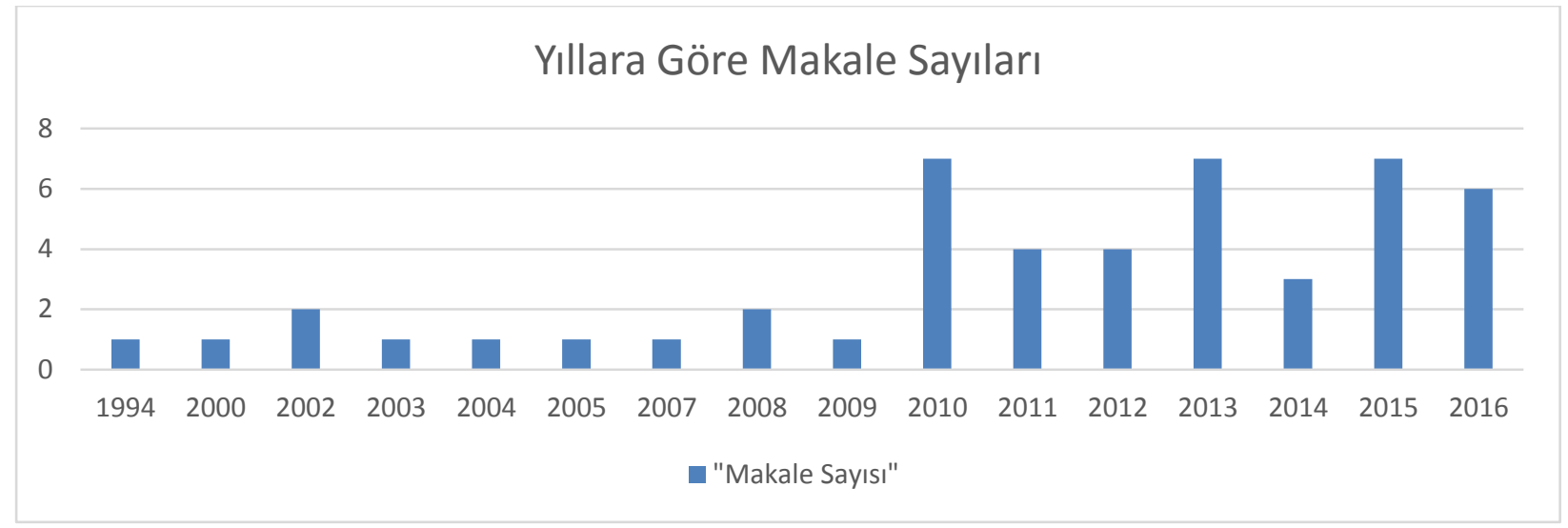

Şekil 2: Çalışmaların Tek Amaçlı ya da Çok Amaçlı Olmasına Göre, Şekil 3 ise Amaçlarına Göre Çalışmaları Sınıflandırmaktadır.

Şekil 2: Tek/ Çok Amaçıı Makale Oranları

\section{TEK/ÇOK AMAÇLı MAKALE ORANLARı}

- Tek amaçı $\quad$ Çok amaçlı

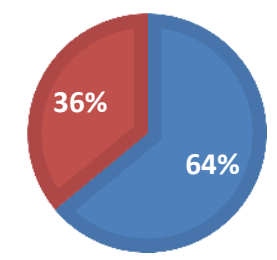

Şekil 3: Amaçlarına Göre Makale Sayıları

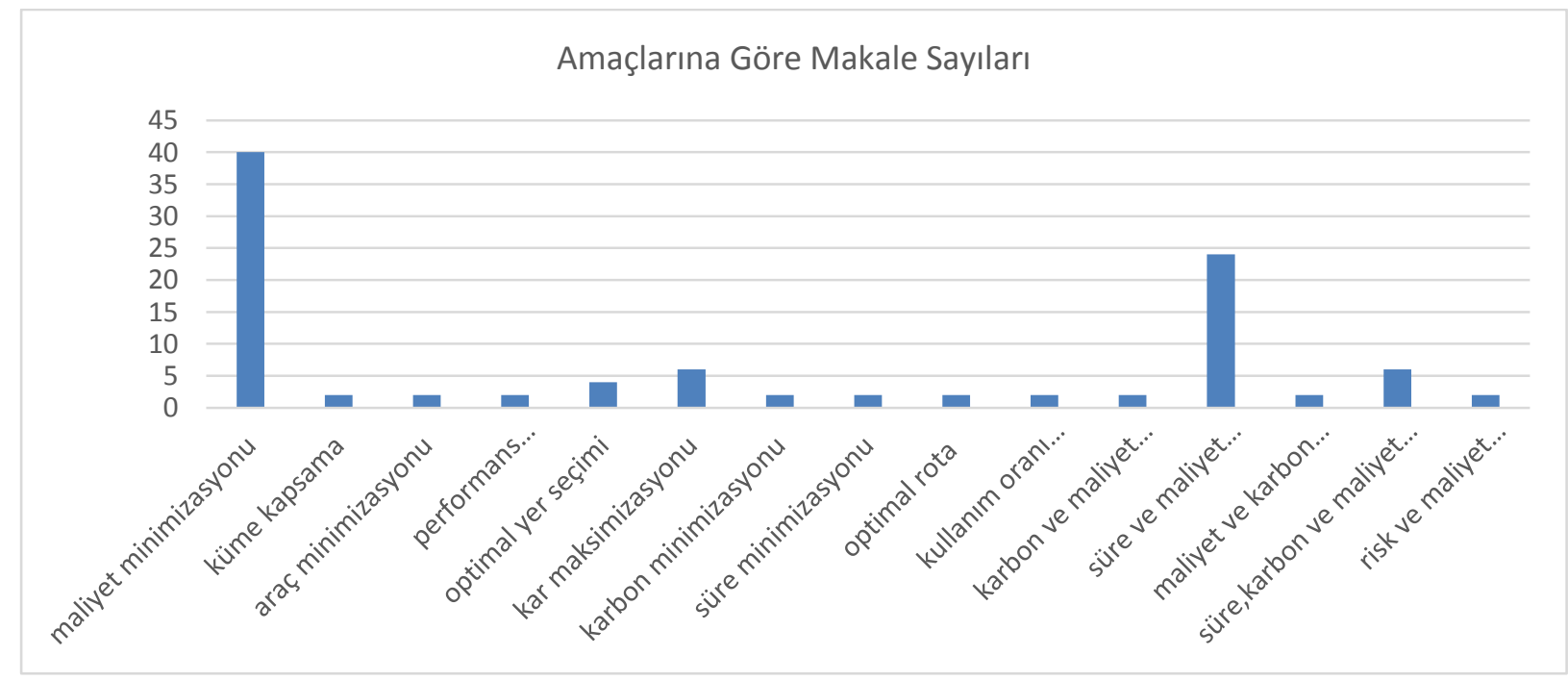

Şekil 4 çalışmaların statik ve dinamik problem türüne göre, Şekil 5 parametrelerinin deterministik veya stokastik olma durumuna göre, Şekil 6 ise problem türüne göre çalışmaları bu durumların kombinasyonu şeklinde sınıflandırmaktadır. 
Şekil 4: Statik/Dinamik Makale Oranları

STATIK / DINAMIK MAKALE ORANLARI

- Statik Dinamik

$14 \%$

Şekil 5: Deterministik/Stokastik Makale Oranları

DETERMINISTIK/STOKASTIK MAKALE ORANLARI

Deterministik $\square$ Stokastik

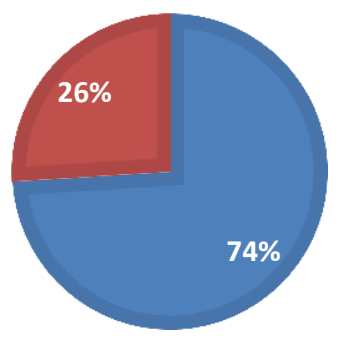

Şekil 6: Problem Özelliğine Göre Makale Yüzdeleri

\section{PROBLEM ÖZELLIĞINE GÖRE MAKALE YÜZDELERI}

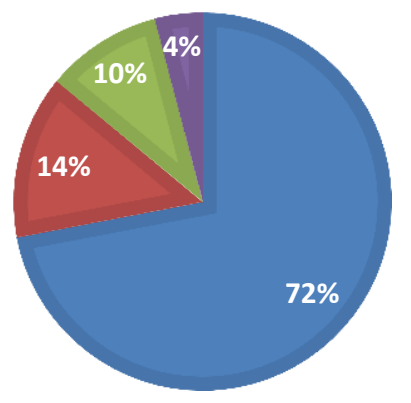

Şekil 7 çalışmaları planlanan zaman ufkuna göre stratejik, operasyonel ve taktiksel olmak üzere üç grupta sınıflandırmaktadır.

Şekil 7: Zaman Ufkuna Göre Makale Oranları 


\section{ZAMAN UFKUNA GÖRE MAKALE ORANLARı}

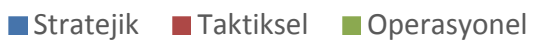

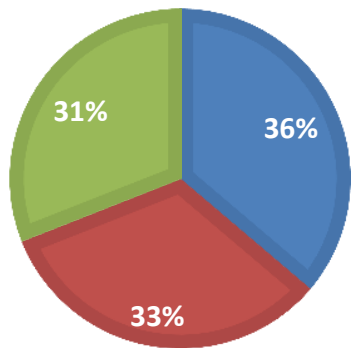

Şekil 8 çalışmaları kullanılan çözüm yöntemine göre sınıflandırmaktadır. Kullanılan çözüm yöntemleri, Tam Sayılı Programlama, Karma Tam Sayılı Programlama, Yapay Zeka (Ajan Temelli Benzetim, Genetik Algoritmalar, Tabu Arama), Sezgisel Yöntemler, Hedef Programlama, Çok Kriterli Karar Verme Yöntemleri, Dal Kesme, Senaryo Analizi, Şans Kısıtlı Stokastik Programlama, Oyun Teorisi ve Dinamik Programlama şeklindedir.

Şekil 8: Çözüm Yöntemlerine Göre Makale Oranları

\section{ÇÖZÜM YÖNTEMLERINE GÖRE MAKALE ORANLARı}

— Tam Sayılı Programlama
Sezgisel
— Hedef Programlama
Dal Kesme

AHP, ELECTRE ve Bulanık AHP

- Karma Tamsayılı Porgramlama

- Senaryo Analizi

Dinamik Programlama

- Yapay Zeka

- Literatür Araştırması

口Şans Kısıtlı Stokastik Porgramlama — Oyun Teorisi

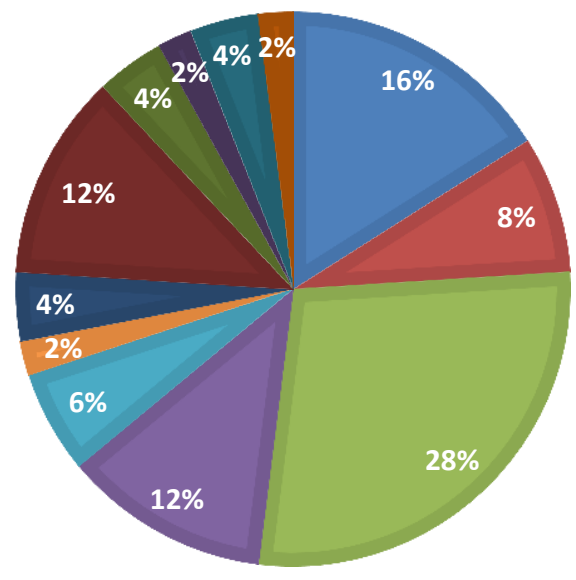

Ayrıca çalışmalar, literatürde çok fazla kullanıldı̆̆ı için bulanık mantık teorisi ve simülasyon kullanılıp kullanılmamasına göre sınıflandırılmıştır. Şekil 9 ve Şekil 10 bulanık mantık ve simülasyon için makale oranlarını göstermektedir.

Şekil 9: Simülasyon İçeren/İçermeyen Makale Oranları 


\section{SIMÜLASYON IÇEREN/IÇERMEYEN MAKALE ORANLARı}

-Yok $\square$ Var

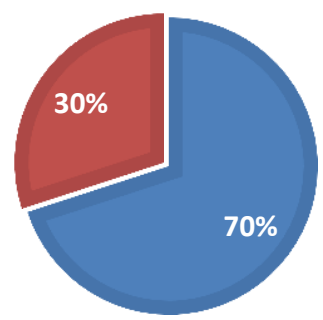

Şekil 10: Bulanık Mantık İçeren/İçermeyen Makale Oranları

BULANıK MANTIK IÇEREN/IÇERMEYEN MAKALE ORANLARı

-Yok - Var

\section{$12 \%$}

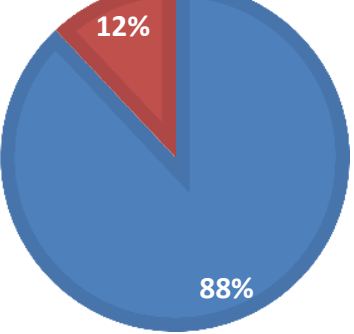

Son olarak çalışmalar, gerçek veri ve başka çalışma verisi kullanılarak uygulanmasına göre sınıflandırılmıştır.

Şekil 11: Veri Türüne Göre Makaleler 


\section{VERI TÜRÜNE GÖRE MAKALE ORANLARı}

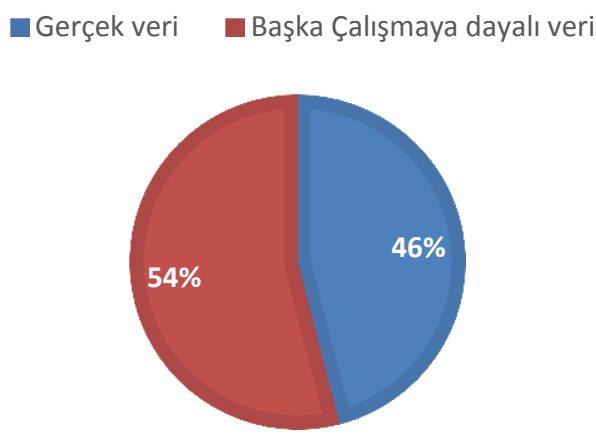

\section{SONUÇLAR VE GELECEK ÇALIŞMALAR}

Bu çalışmada, intermodal taşımacılık problemi ele alınarak literatürde mevcut modeller, önerilen çözüm yöntemleri ve farklı performans göstergeleri sınıflandırılarak analiz edilmiştir. Mevcut çalışmalar incelendiğinde, ekonomik performansı arttırma, trafik sıkışıklığını azaltma ve yol güvenliğini arttırma avantajlarına sahip, özellikle uzun mesafeli taşımalar için son derece uygun, erişilebilir ve çevre dostu olarak kabul edilen intermodal taşımacılı̆̆a artan bir ilgi mevcuttur. Son yirmi yılda artan sayıdaki çalışmaları incelediğimizde, geçmişteki çalışmaların çoğunlukla karayolu-demiryolu intermodal taşımacılık problemleri üzerinde yoğunlaşmış olmalarına rağmen, son zamanlarda çevresel faktörler üzerine yapılan çalışmalar dikkat çekmektedir. Bu anlamda Avrupa Birliğinin sağlamış olduğu destek ve projeler önem arz etmektedir.

Intermodal yük taşımacılığı araştırmacılar için verimli bir alandır. İntermodal taşımacılık üzerine yapılan çalışma sayısı her geçen gün artmaktadır. Çalışmalar amaçlarına göre tek amaçlı ve çok amaçlı olmak üzere ikiye ayrılmaktadır ve tek amaçlı modeller literatürde daha çok yer almaktadır öyle ki bu amaç maliyet minimizasyonudur. Buna göre, intermodal taşımacılık üzerine sadece maliyet minimizasyonu odağından çıkıp taşıma süresi minimizasyonu ve özellikle de çevreyle dost taşıma sistemlerinin ön plana çıkacağı çok amaçlı modellere ihtiyaç duyulmaktadır. Türkiye gibi jeopolitik olarak önemli yer tutan orta gelir düzeyindeki ülkeleri ilerletecek bir seçenek olan intermodal taşımacılığın en iyi şekilde yapılabilmesi için lojistik üssü köylerinin yerleri seçimi, araç ve konteyner tipini ve çevreye duyarlı rotaları belirleyen toplu ağ tasarımı çalışmaları yapılmalıdır. Zaman ufkuna göre üç sınıftan da çalışmaların çıkması önemlidir, bu sınıflandırmaya bakıldığında her sınıfa düşen makale sayısı aşağı yukarı eşittir. Ancak belirsizlik ve bilgi eksikliği nedeniyle yeni yapılacak olan çalışmalar deterministik ve statik olmak yerine her durumu ve riski göze alacak şekilde dinamik ve stokastik şekilde yapılmalıdır. Ayrıca riski minimize etmek için bulanık mantık ve simülasyon yöntemlerinden yararlanılmalıdır. Literatüre bu alanda önemli katkılar yapılmış olsa da, mevcut çalışmaların kapsadığı alanlardaki çalışma sayısı halen sınırlıdır. Eşzamanlı olarak çalışan çoklu taşıma modlarının operasyonel entegrasyonu, iki taşıma modu arasındaki çizelge koordinasyonu, ve intermodal taşıma zincirinin önemli bir unsuru olan depoları içeren problemler literatürde yeterince ele alınmamıştır. Ayrıca, önerilen yöntemler gerçek-hayat intermodal taşımacılık ağlarının doğasında mevcut olan karmaşık yapıyı modellemede çoğunlukla yetersiz kalmaktadırlar. Özellikle, mevcut modellerin çoğu bazı varsayımlarla basitleştirilmiş sınırlı problemleri tanımlayabilmektedir. Gerçek dünya problemlerinin, taşıma akışlarının devam eden artışı ile büyük ölçekli ve karmaşık olması nedeniyle, gelecekteki araştırma konularının makul bir süre içinde analitik çözümler sunarak büyük ölçekli problemlerin pratik hayat kısıtlarını ele alabilmesi gerekmektedir. Eğer intermodal taşımacılık problemlerine etkin çözümler üretmekte kullanılabilen iyi sezgiseller geliştirildiği taktirde toplam çözüm süresi sorunu üzerine büyük bir gelişme elde edilebilir.

\section{KAYNAKLAR}

Arnold, P., Peeters, D., \& Thomas, I. (2004). Modelling a rail/road intermodal transportation system. Transportation Research Part E: Logistics and Transportation Review, 40(3), 255-270.

Assadipour, G., Ke, G. Y., \& Verma, M. (2015). Planning and managing intermodal transportation of hazardous materials with capacity selection and congestion. Transportation Research Part E: Logistics and Transportation Review, 76, 45-57.

Bauer, J., Bektaş, T., \& Crainic, T. G. (2010). Minimizing greenhouse gas emissions in intermodal freight transport: an application to rail service design. Journal of the Operational Research Society, 61(3), 530-542. 
Baykasoğlu, A., \& Subulan, K. (2016). A multi-objective sustainable load planning model for intermodal transportation networks with a reallife application. Transportation Research Part E: Logistics and Transportation Review, 95, 207-247.

Bhattacharya, A., Kumar, S. A., Tiwari, M. K., \& Talluri, S. (2014). An intermodal freight transport system for optimal supply chain logistics. Transportation Research Part C: Emerging Technologies, 38, 73-84.

Bierwirth, C., Kirschstein, T., \& Meisel, F. (2012). On transport service selection in intermodal rail/road distribution networks. BuR-Business Research, 5(2), 198-219.

Bruns, F., \& Knust, S. (2012). Optimized load planning of trains in intermodal transportation. OR spectrum, 34(3), 511-533.

Chang, C. C., \& Lai, T. C. (2013). Carbon allowance allocation in the transportation industry. Energy policy, 63, 1091-1097.

Chang, T. S. (2008). Best routes selection in international intermodal networks. Computers \& operations research, 35(9), 2877-2891.

Cho, J. H., Kim, H. S., \& Choi, H. R. (2012). An intermodal transport network planning algorithm using dynamic programming-a case study: from Busan to Rotterdam in intermodal freight routing. Applied Intelligence, 36(3), 529-541.

Choong, S. T., Cole, M. H., \& Kutanoglu, E. (2002). Empty container management for intermodal transportation networks. Transportation Research Part E: Logistics and Transportation Review, 38(6), 423-438.

Demir, E., Burgholzer, W., Hrušovský, M., Arıkan, E., Jammernegg, W., \& Van Woensel, T. (2015). A green intermodal service network design problem with travel time uncertainty. Transportation Research Part B: Methodological.

Di Febbraro, A., Sacco, N., \& Saeednia, M. (2016). An agent-based framework for cooperative planning of intermodal freight transport chains. Transportation Research Part C: Emerging Technologies, 64, 72-85.

Duan, X., \& Heragu, S. (2015, January). Carbon Emission Tax Policy in an Intermodal Transportation Network. In IIE Annual Conference. Proceedings (p. 566). Institute of Industrial Engineers-Publisher.

García, J., Florez, J. E., Torralba, Á., Borrajo, D., López, C. L., García-Olaya, Á., \& Sáenz, J. (2013). Combining linear programming and automated planning to solve intermodal transportation problems. European Journal of Operational Research, 227(1), 216-226.

Ghane-Ezabadi, M., \& Vergara, H. A. (2016). Decomposition approach for integrated intermodal logistics network design. Transportation Research Part E: Logistics and Transportation Review, 89, 53-69.

Hanaoka, S., \& Kunadhamraks, P. (2009). Multiple criteria and fuzzy based evaluation of logistics performance for intermodal transportation. Journal of Advanced Transportation, 43(2), 123.

Janic, M. (2007). Modelling the full costs of an intermodal and road freight transport network. Transportation Research Part D: Transport and Environment, 12(1), 33-44.

Kalasová, A., Kapusta, J., \& Toman, P. (2016). A Model of Transatlantic Intermodal Freight Transportation Between the European Continent and the United States 1/Model transatlantskog intermodalnog prijevoza tereta izmeðu Europe i Sjedinjenih Americkih Drzava. Nase More, 63(1), 5 .

Kalinina, M., Olsson, L., \& Larsson, A. (2013). A Multi Objective Chance Constrained Programming Model for Intermodal Logistics with Uncertain Time. International Journal of Computer Science Issues, 10(6), 35-44.

Kayikci, Y. (2010). A conceptual model for intermodal freight logistics centre location decisions. Procedia-Social and Behavioral Sciences, 2(3), 6297-6311.

Li, L., Negenborn, R. R., \& De Schutter, B. (2015). Intermodal freight transport planning-a receding horizon control approach. Transportation Research Part C: Emerging Technologies, 60, 77-95.

Lin, C. C., \& Lin, S. W. (2016). Two-stage approach to the intermodal terminal location problem. Computers \& Operations Research, 67, 113-119.

Macharis, C., Caris, A., Jourquin, B., \& Pekin, E. (2011). A decision support framework for intermodal transport policy. European Transport Research Review, 3(4), 167-178.

Meisel, F., Kirschstein, T., \& Bierwirth, C. (2013). Integrated production and intermodal transportation planning in large scale productiondistribution-networks. Transportation Research Part E: Logistics and Transportation Review, 60, 62-78.

Meng, Q., \& Wang, X. (2011). Intermodal hub-and-spoke network design: incorporating multiple stakeholders and multi-type containers. Transportation Research Part B: Methodological, 45(4), 724-742.

Morlok, E. K., \& Spasovic, L. N. (1994). Redesigning rail-truck intermodal drayage operations for enhanced service and cost performance. In Journal of the Transportation Research Forum (Vol. 34, No. 1).

Parola, F., \& Sciomachen, A. (2005). Intermodal container flows in a port system network:: Analysis of possible growths via simulation models. International journal of production economics, 97(1), 75-88.

Puettmann, C., \& Stadtler, H. (2010). A collaborative planning approach for intermodal freight transportation. OR spectrum, 32(3), 809-830.

DOI:10.17261/Pressacademia.2017.387

19

PressAcademia

Procedia 
Qu, Y., Bektaş, T., \& Bennell, J. (2016). Sustainability SI: multimode multicommodity network design model for intermodal freight transportation with transfer and emission costs. Networks and Spatial Economics, 16(1), 303-329.

Rajkovic, R., Zrnic, N., \& Stakic, D. (2016). Application of mathematical model for container transport flow of goods: from Far east to Serbia. Tehnički vjesnik, 23(6), 1739-1746.

Regmi, M. B., \& Hanaoka, S. (2012). Assessment of intermodal transport corridors: Cases from North-East and Central Asia. Research in Transportation Business \& Management, 5, 27-37.

Resat, H. G., \& Turkay, M. (2015). Design and operation of intermodal transportation network in the Marmara region of Turkey. Transportation Research Part E: Logistics and Transportation Review, 83, 16-33.

Rothenbächer, A. K., Drexl, M., \& Irnich, S. (2016). Branch-and-Price-and-Cut for a Service Network Design and Hub Location Problem. European Journal of Operational Research.

Saeed, N. (2013). Cooperation among freight forwarders: Mode choice and intermodal freight transport. Research in Transportation Economics, 42(1), 77-86.

Santos, B. F., Limbourg, S., \& Carreira, J. S. (2015). The impact of transport policies on railroad intermodal freight competitiveness-The case of Belgium. Transportation Research Part D: Transport and Environment, 34, 230-244.

Sawadogo, M., \& Anciaux, D. (2010, April). Reducing the environmental impacts of intermodal transportation: a multi-criteria analysis based on ELECTRE and AHP methods. In 3rd International Conference on Information Systems, Logistics and Supply Chain Creating value through green supply chains (p. 224).

Southworth, F., \& Peterson, B. E. (2000). Intermodal and international freight network modeling. Transportation Research Part C: Emerging Technologies, 8(1), 147-166.

Verma, M., \& Verter, V. (2010). A lead-time based approach for planning rail-truck intermodal transportation of dangerous goods. European Journal of Operational Research, 202(3), 696-706.

Verma, M., Verter, V., \& Zufferey, N. (2012). A bi-objective model for planning and managing rail-truck intermodal transportation of hazardous materials. Transportation research part E: logistics and transportation review, 48(1), 132-149.

Verma, M., Verter, V., \& Zufferey, N. (2013). A Meta-heuristic approach to rail-truck intermodal transportation of hazardous materials. In proceedings of international conference on advances in communication, network, and computing.

Wang, X., \& Regan, A. C. (2002). Local truckload pickup and delivery with hard time window constraints. Transportation Research Part B: Methodological, 36(2), 97-112.

Yang, X., Low, J. M., \& Tang, L. C. (2011). Analysis of intermodal freight from China to Indian Ocean: a goal programming approach. Journal of Transport Geography, 19(4), 515-527.

Zehendner, E., \& Feillet, D. (2014). Benefits of a truck appointment system on the service quality of inland transport modes at a multimodal container terminal. European Journal of Operational Research, 235(2), 461-469.

Zhang, C., Liu, J., Wan, Y. W., Murty, K. G., \& Linn, R. J. (2003). Storage space allocation in container terminals. Transportation Research Part B: Methodological, 37(10), 883-903.

Zhang, M., Janic, M., \& Tavasszy, L. A. (2015). A freight transport optimization model for integrated network, service, and policy design. Transportation Research Part E: Logistics and Transportation Review, 77, 61-76.

Ziliaskopoulos, A., Wardell, W., 2000. An intermodal optimum path algorithm for multimodal networks with dynamic arc travel times and switching delays. European Journal of Operational Research, 125 (3), 486-502. 